\title{
VASPITNI POSTUPCI RODITELJA KAO ČINIOCI AKTUALIZACIJE DAROVITOSTI
}

Rad nudi pregled razultata istraživanja relacija vaspitnih postupaka roditelja i aktualizacije potencijala darovitog deteta, uzimajući u obzir dvodimenzionalne modele vaspitanja. Kad je reč o afektivnoj dimenziji, zapaža se visok stepen konzistentnosti empirijskih nalaza koji svedoče o važnosti emocionalne topline i prihvatajućeg odnosa roditelja u razvoju visokih sposobnosti deteta. Sa druge strane, istraživanja uloge kontrole u vaspitanju darovitog deteta generišu različite zaključke. Naime, iako ne postoji sumnja u vezi shvatanja kontrole kao usmeravanja i vođenja deteta, izvesne nedoumice proizilaze iz pokušaja utvrđivanja optimalnog intenziteta ove dimenzije. Naposletku, iako je teško dati jednoznačan odgovor i o najprimerenijoj kombinaciji vaspitnih postupaka roditelja, otuda što se ovo pitanje mora razmatrati u skladu sa domenom manifestovanja darovitosti, te uzrastom darovitog deteta, istraživanja ovog problema u najvećem broju slučajeva sugerišu pozitivnu povezanost autoritativnog vaspitnog stila i razvoja darovitosti.

Ključne reči: darovitost, vaspitni postupci roditelja, dvodimenzionalni modeli vaspitanja, autoritativni vaspini stil.

Zaslugom „kontekstualističkih“ koncepcija skrenuta je pažnja na dinamičnu prirodu darovitosti koja nameće potrebu za razmatranjem ovog fenomena u relaciji sa sredinskim kontekstom. Preciznije rečeno, za razliku od nekadašnjeg 'fiksiranja' darovitosti unutar intrapsihičkih okvira, moderna shvatanja insistiraju na posmatranju ovog fenomena kao razvojnog procesa koji beleži postupno uzrastanje potencijala u izuzetan učinak. Ova transformacija je u značajnoj meri determinisana specifičnom konstelacijom sredinskih faktora, među kojima se u prvom redu ističu združeni uticaji porodice i škole. Naime, meta-analize svetskih istraživanja na temu obrazovanja darovitih izvode zaključak da u odsustvu podrške porodice škola najčešće podbacije u pokušajima celovitog razvijanja potencijala darovite dece (Freeman, 1998), zbog 
čega se na pojedinim mestima navodi da se uloga porodice kao sredinskog faktora razvoja darovitosti vrednuje više nego uloga škole (Cross \& Coleman, 2005).

Naivne teorije o ulozi porodice u konstituisanju talenta iznedrile su shvatanja o darovitoj deci kao „produktu“ ambicioznih roditelja. Naime, određeni segmenti literature o ovoj problematici otkrivaju da je logici zdravog razuma blisko shvatanje po kojem svaki oblik darovitosti počiva na roditeljskoj inicijativi i podstreku, zbog čega je darovitoj deci uskraćeno pravo na „normalno detinjstvo“ (Winner, 1996). Istini za volju, implicitna teza o ,isforsiranoj darovitosti“ ne predstavlja opštu pojavu i tipičnija je za Zapadna društva koja su sklona naznačavanju nižih standarda akademske uspešnosti, u odnosu na zemlje Istoka (Hau \& Salili, 1996; Stevenson \& Lee, 1996; Stevenson, Lee \& Stigler, 1986). No, zanimljivo je da su slična tumačenja porekla darovitosti obitivala i unutar naučnih krugova, te da su u 'votsonovskom' maniru isticala kako „u odgovarajućem okruženju skoro svako...može ovladati raznim intelektualnim veštinama do nivoa izuzetnosti“ (Howe, 1990, prema Freeman, 2000, str. 575). Neka mesta u literaturi, takođe, navode da su mnogi slučajevi darovitosti proizašli iz „efektivnog roditeljskog zalaganja“ (Cambel, 1997).

Načelni stav nauke o ovoj problematici svodi se na kvalifikovanje porodice kao „esencijalnog konteksta“ za razvoj darovitosti (Freeman, 2000), no istovremeno se potcrtava da se nesumnjiv uticaj porodičnih faktora ne može proglašavati generatorskim (Freeman, 2000; Winner, 1996). Drugim rečima, mnogo je uputnije konstatovati da povoljne porodične prilike ne predstavljaju ishodište darovitosti, već da samo potpomažu preobraćanje visokih potencijala u zapaženi učinak u određenom domenu. U skladu sa teorijskim okvirom „diferenciranih modela darovitosti“, doprinos porodice u razvoju talenta mogao bi se opisati i u teminima "katalizatora“ odnosno „moderatora“ razvojnog procesa, koji kao polaznu osnovu ima visoke specifične sposobnosti, a kao krajnji ishod izuzetno postignuće u određenoj oblasti (Gagné, 2005; Heller, Perleth \& Lim, 2005). Dakle, ma koliko napora roditelji investirali u usmeravanje detetovog razvoja u pravcu izuzetnosti, njegovo postignuće neće nositi etiketu darovitosti ukoliko izostaje potpora u vidu visokih sposobnosti. Sa druge strane, dete nadprosečnih potencijala će teško dosegnuti krajnje domete svojih sposobnosti, ukoliko odrasta u neadekvatnom porodičnom okruženju.

Teorijska razmatranja prirode uticaja porodice na razvoj darovitosti $u$ saglasnosti su sa zaključcima empirijskih studija ove problematike, koje u najvećem 
broju slučajeva ispituju percepciju porodičnih prilika darovite dece, primenom različitih tipova upitnika (Schilling, Sparfeldt \& Rost, 2006) ${ }^{1}$. Naime, s obzirom na činjenicu da su nacrti istraživanja u ovoj oblasti većinom sledili načela korelacionih istraživanja, na više mesta u literaturi se ističe da se o delovanju porodičnih faktora na aktualizaciju potencijala darovitog deteta ne može govoriti u terminima kauzalalnog odnosa, već samo uzajamne povezanosti koja je vrlo verovatno dvosmernog tipa, što znači da odgovarajući roditeljski uticaji predstavljaju antecedente razvoja talenta, ali i da spoznaja o darovitosti deteta doprinosi nastanku specifične vaspitne klime (Cornell \& Grossberg, 1987). Dvosmeran uticaj između potencijala i porodičnih "moderator" varijabli naznačava i Minhenski model darovitosti (vidi poglavlje o kontekstualističkim koncepcijama darovitosti). Neki autori ovaj mehanizam povratne sprege objašnjavaju shvatanjem detetove darovitosti kao potencijalnog stresora koji doprinosi specifičnoj strukturi i organizaciji porodičnog sistema (May, 1994, prema Schilling, et al., 2006).

\section{VASPITNI POSTUPCI RODITELJA SA DAROVITIM DETETOM: DVODIMENZIONALNI PRISTUP}

Isticanje važnosti afektivne interakcije roditelja i dece u kontekstu detetovog intelektualnog razvoja seže daleko u prošlost psihološke nauke. Naime, još su klasici psihološke literature isticali ulogu emocionalne responsivnosti roditelja u razvoju detetovog „racionalnog mišljenja“ (Freud, 1938, prema Landau \& Weissler, 1993, str. 133), kao i vezu između emocionalne deprivacije deteta i njegovog zaostajanja u mentalnom razvoju (Freud \& Burlingham, 1944, Spitz, 1946, svi prema Landau \& Weissler, 1993). Verovatno su ova fundamentalna saznanja o relevantnosti adekvatnog reagovanja roditelja na potrebu deteta za ljubavlju i afektivnom vezanošću doprinela konstituisanju linije istraživanja koja je analizirala relacije vaspitnih stilova roditelja i darovitosti dece.

$\mathrm{S}$ obzirom na popularnost dvodimenzionalnog pristupa u sistematizovanju

1 Upitnik, kao dominantna tehnika prikupljanja podataka o porodičnim prilikama darovite dece, najčešće ima čvrstu strukturu koja odgovara strukturi psihološkog testa, premda se neretko koriste i upitnici „labavije“ strukture koje neki autori nazivaju ,intervjui preneseni na papir“ (Fajgelj, 2004, str. 309). Otuda ne čudi što pojedini autori ističu da upitnici porodičnih prilika, primenjeni na uzorku darovite dece, variraju od temeljno razrađenih (ekstenzivnih), do jednoajtemskih (Schilling et al., 2006). 
brojnih varijeteta vaspitnih postupaka roditelja, čiji su glavni protagonisti Šefer i Baumrindova, mnoga istraživanja porodičnih prilika darovite dece su kao nezavisne varijable naznačavala afektivnu i kontrolnu dimenziju vaspitanja, koje su koncipirane kao ortogonalne i bipolarno omeđene. Afektivna dimenzija se određuje kao stepen otvorenosti roditelja u iskazivanju naklonosti prema detetu, te senzitivnosti za njegove želje i potrebe (Paris, Morrison \& Miller, 2006), koje variraju u rasponu od hladnog do toplog vaspitanja. Hladan, odbijajući roditelj zauzima distancu u odnosu prema detetu, ne prihvata dečije pokušaje približavanja, pokazuje prijemčivost za metode kažnjavanja (uključujući i fizičku kaznu), te zauzdanost u komunikaciji sa detetom (malo razgovara sa detetom i ne obrazlaže vlastite postupke). Nasuprot tome, topao roditelj se odlikuje prihvatajućim odnosom prema detetu, koji koji se manifestuje kao otvorenost u iskazivanju emocija, prihvatanje detetovog približavanja, učestalost razgovora sa detetom uz stalno prisutnu tendenciju roditelja ka obrazlaganju vlastitih postupaka, te prijemčivost za različite oblike pozitivnog potkrepljivanja deteta (Kodžopeljić, Štula i Genc, 2008). Istraživanja relacija afektivne dimenzije vaspitanja i kognitivnog aspekta razvoja deteta, iznedrila su prilično jasno viđenje uloge ove dimenzije vaspitanja u aktualizaciji detetovih potencijala. Naime, nalazi različitih istraživanja ovog problema sugerišu važnost emocionalne topline roditelja u razvijanju detetovih intelektualnih potencijala, odnosno u podsticanju njegove darovitosti (Bradly \& Caldwell, 1976, Vernon, 1979, svi prema Landau \& Weissler, 1993; Cornell \& Grossberg, 1987; Karnes \& Shwedel, 1987; OlszewskiKubilius, 2002; Weissler \& Landau, 1992). Osim toga, afektivna dimenzija se pokazala pozitivno koreliranom i sa nivoom jezičkog i kognitivnog razvoja deteta na predškolskom uzrastu, te njegovim docnijim akademskim učinkom (Karnes et al., 1961, prema Winner, 1996).

Što se dimenzije kontrole tiče, ograničavajuće vaspitanje, kao jedan od njenih ekstrema, odlikuje se sklonošću roditelja ka naznačavanju brojnih pravila ponašanja, te insistiranju na njihovom doslednom pridržavanju, što imlicira nizak stepen psihičke i fizičke slobode deteta. Popustljivo vaspitanje, kao svojevrstan antipod visokoj kontroli, opisuje se u terminima niske kontrole, te naglašene fleksibilnosti u definisanju pravila ponašanja (Kodžopeljić, Štula i Genc, 2008). Nalazi različitih istraživanja upućuju na poteškoće utvrđivanja jednoznačnih relacija između intenziteta sputavanja deteta različitim pravilima i ograničenjima i stepena 
razvijenosti njegovog talenta, premda se na pojedinim mestima ovaj problem nastoji unekoliko pojednostaviti ukazivanjem na vezu između podbacivanja darovitog deteta i ekstrema kontrolne dimenzije, poput preterane permisivnosti, odnosno restriktivnosti u vaspitanju (Khatena, 1982, prema Peterson, 2011). Naime, dok određeni broj istraživanja konstatuje povezanost popustljivosti u vaspitanju i lične autonomije deteta, koja doprinosi jačanju intrinzičkog motiva postignuća, druga linija istraživanja naglašava vezu restriktivnih vaspitnih postupaka i razvijanja osećanja odgovornosti deteta. Dakle, dok jedna linija istraživanja talenat povezuje sa niskim stepenom kontrole, posredstvom nezavisnosti dečijeg mišljenja i ponašanja koje snaže intrinzičku motivaciju, druga linija istraživanja razvoj darovitosti smatra nezamislivim u odsustvu samodiscipline i odgovornosti, koje se vezuju za naznačavanje velikog broja vaspitnih pravila.

U okviru prve grupe istraživanja se nailazi na nalaze da majke intelektualno darovite dece u mnogo većoj meri podstiču detetovu autonomiju i nezavisnost u odnosu na majke dece prosečne inteligencije (Bradly \& Caldwell, 1976, prema Landau \& Weissler, 1993; Piper \& Naumann, 1974), kao i na nalaze koji ističu da vaspitanje darovite dece ima predznak izražene responsivnosti za potrebe deteta, te niskog stepena restriktivnosti (Feldman \& Goldsmith, 1991). Određeni broj istraživanja se usaglašava u zapažanjima da porodice bez akademski darovitog deteta pokazuju veću prijemčivost za autoritarni stil vaspitanja, u odnosu na porodice sa akademski darovitim detetom (Geppert \& Kuster, 1983; Freeburg \& Payne, 1967; Weissler \& Landau, 1992).

U okviru druge grupe istraživanja nailazi se na rezultate koji povoljnim sredinskim prilikama za razvoj talenta proglašavaju visoke zahteve i kontrolu u vaspitanju, za koje se smatra da doprinose većoj odgovornosti (Vernon, 1979, prema Landau \& Weissler, 1993), kao i na rezultate koji ukazuju da su roditelji visoko inteligentne dece, koja pri tome ne naginju kreativnosti, skloni naznačavanju strogih pravila u vaspitanju i doslednom insistiranju na njihovom pridržavanju, što rezultira i naglašenim tendencijama dece ka konformiranju (Getzels \& Jackson, 1962). Ovoj grupi pripadaju i empirijski nalazi koji ukazuju da visok nivo roditeljske kontrole unapređuje detetove veštine samoregulacije, što se pozitivno odražava na njegovo akademsko postignuće (Cooney, 1998, prema Paris et al., 2006).

Mogući način premošćavanja oprečnih nalaza o ulozi roditeljske kontrole 
u razvoju darovitosti podrazumeva njeno povezivanje sa afektivnom dimenzijom. Naime, s obzirom da se značenje kontrole značajno menja u zavisnosti od toga da li je vezujemo uz toplo ili hladno vaspitanje, to jest u odnosu na „emocionalni kontekst u kome se ostvaruje kontrola aktivnosti deteta“" (Rot, 1994, str. 116), vaspitni postupci roditelja mogu se jasnije sagledati kroz kombinaciju krajnjih tačaka dveju dimenzija, čime dolazimo do pojma vaspitnog stava (Genc, 1988). Naime, restriktivnost koja je ukombinovana sa emocionalnom hladnoćom, za šta je u pojedinim teorijskim modelima vaspitanja namenjen termin autoritarnost (Baumrind, 1971, prema Lacković-Grgin, 2006), predstavlja svojevrsno sredstvo diktature koje osujećuje detetove pokušaje osamostaljivanja i uspostavljanja lične autonomije (Genc, 1988), što nesumnjivo otežava preobraćanje visokih potencijala deteta u izuzetan učinak. Sa druge strane, vaspitni stavovi koji se opisuju u terminima emocionalne topline i ograničavanja u vaspitanju, a koji se označavaju terminom autoritativnost (Baumrind, 1971, prema Lacković-Grgin, 2006), doprinose pozitivnom vrednosnom konotiranju termina „kontrola“, te njegovom povezivanju sa usmeravanjem i vođenjem deteta, što potpomaže proces razvoja darovitosti. Ovo u priličnoj meri korespondira sa shvatanjima autoritativnog vaspitnog stila kao najefektnije kombinacije vaspitnih postupaka za preobraćanje visokih potencijala (Fine, 1977, Karnes et al., 1961, svi prema Winner, 1996; Dwairy, 2004), kao i opisima kontrole u vaspitavanju darovitih kao ograničavanja koje ne sme imati karakter „parališuće prinude“, ali ni permisivosti koja poništava bilo kakav oblik zabrane (Weissler \& Landau, 1992). Osim toga, i čuvena Blumova studija o razvoju talenta ističe porodičnu podršku udruženu sa disciplinom kao važan faktor realizacije potencijala darovitih (Bloom, 1985). Blagotvoran uticaj autoritativnog vaspitnog stila konstatovan je i u aspektu jačanja samopoštovanja i samopouzdanja deteta (Holmbeck, 1996, Litovsky \& Dusek, 1985, svi prema McKinney \& Renk, 2008), što upotpunjuje predstavu o povoljnosti ovakve kombinacije vaspitnih postupaka za razvoj darovitosti. Osim što ukazuju na pozitivnu koreliranost autoritativnog vaspitnog stila i školskog postignuća deteta na nivou srednje škole, neka istraživanja, sa druge strane, upućuju i na zaključak da se u slučaju autoritarnog i permisivnog vaspitnitnog stila zapaža negativan smer povezanosti sa školskim ocenama (Dornbuch et al., 1987).

No, čak i ako zaključimo da opštu karakteristiku vaspitanja darovite dece predstavlja preimućstvo autoritativnog vaspitnog stila, odnosno emocionalne topline 
udružene sa vođenjem i usmeravanjem deteta, pitanje najprimerenijeg vaspitnog stila za podsticanje darovitosti nije dobilo konačan odgovor. Ovakvo zapažanje proizilazi iz poznavanja rezultata istraživanja koji svedoče o različitosti vaspitnih postupaka roditelja $\mathrm{u}$ aspektu intelektualnog usmeravanja i vođenja deteta, u zavisnosti od domena manifestovanja darovitosti. Naime, ovi nalazi sugerišu da roditelji dece koja su darovita u domenu muzike imaju najdirektivniji pristup, da su roditelji dece koja su darovita u domenu vizuelnih umetnosti u najmanjoj meri direktivni, dok se za roditelje akademski darovite dece ispostavilo da su u pogledu direktivnosti negde između prethodne dve grupe (Bloom, 1985). Kad je reč o roditeljima dece darovite $u$ akademskim domenima, njihov „srednji način“ ophođenja prema deci podrazumevao je da su poput roditelja muzički darovite dece podsticali naporan rad, postavljajući visoke standarde uspešnosti, ali da su slično roditeljima dece darovite u domenu vizuelnih umetnosti ispoljavali priličnu indolentnost prema vrsti domena manifestovanja darovitosti, favorizujući samoaktualizaciju kao takvu. U nekim starijim istraživanjima koja su u fokusu razmatranja imala razlike u vaspitnim stilovima roditelja intelektualno i kreativno darovite dece, konstatovan je mnogo viši stepen permisivnosti u vaspitanju kreativne dece, koja se opisuje kao odsustvo pritiska za konformiranjem, te kao svesrdno podstrekivanje detetove autonomije, što se smatra naročito podsticajnim za razvoj kreativnih potencijala (Albert, 1978, prema Chan, 2008; Getzels \& Jackson, 1962).

Osim što se primerenost vaspitnih stilova za razvoj darovitosti mora vrednovati u odnosu na konkretan domen talenta, ovo pitanje nameće još jednu vrstu relativizacije. Naime, kao što je poznato, primerenost vaspitnih postupaka se menja sa uzrastom deteta, te bi odrastanje deteta trebalo biti praćeno slabljenjem restriktivnosti i kontrole u vasptanju (Genc, 1988). No, iako bismo mogli očekivati da akademska darovitost na starijim uzrastima ostvaruje relaciju sa popustljivim vaspitanjem, nalazi istraživanja sugerišu da se autoritativni vaspitni stil pokazuje predominantnim čak i u periodu kasne adolescencije, te da ostvaruje pozitivnu korelaciju sa opštim uspehom na početnim godinama studija (Hickman, Bartholomae \& McKenry, 2000). No, u ovom slučaju se, najverovatnije, radi o pethodno pomenutoj kontroli koja ima predznak intelektualnog usmeravanja i vođenja deteta, a ne disciplinovanja kroz naznačavanje pravila ponašanja, s obzirom da uzrast ispitanika implicira da je reč o gotovo formiranim ličnostima. 
Naposletku, ono što dodatno otežava generisanje jednoznačnog odgovora o najprimerenijem obrascu vaspitanja darovite dece je shvatanje po kojem je za razvoj darovitosti mnogo važnija uzajamna usaglašenost vaspitnih postupaka roditelja, nego konkretan vaspitni stil (Rimm \& Lowe, 1988). Kao što mnoge teorije pretpostavljaju, a ishodi empirijskih provera potvrđuju, vaspitni stilovi roditelja se neretko razlikuju kako u odnosu na pol roditelja, tako i u odnosu na pol deteta (Conrade \& Ho, 2001; Phares, 1999; Tein, Roosa \& Michaels, 1994). Verovatno najsažetiji opis pomenutih razlika nudi istraživanje Rasela i saradnika (Russel et al., 1998) koje ukazuje na veću prijemčivost majki za autoritativni stil vaspitanja, odnosno frekventniju zastupljenost autoritarnog vaspitnog stila među očevima. Sa druge strane, autoritarni vaspitni stil se češće primenjuje u vaspitavanju sinova, dok se u vaspitavanju ženske dece u mnogo većoj meri poseže za vaspitnim postupcima koji imaju predznak autoritativnosti. No, i pored nalaza koji sugerišu da je razilaženje roditelja u načinu ostvarivanja vaspitnih ciljeva vrlo česta pojava, inkongruentnost vaspitnih stilova roditelja se pokazala značajno povezanom sa mnogim negativnim karakteristikama razvoja deteta, poput niskog samopoštovanja, loše adaptiranosti na školske zahteve, te slabog školskog učinka (Johnson, Shulman \& Collins, 1991), što korespondira sa shvatanjima koja ističu važnost uzajamne usaglašenosti vaspitnog stila roditelja za razvoj darovitosti. Uzajamna usklađenost vaspitnih stilova roditelja se na nekim mestima smatra značajnijom od samog tipa preovlađujućeg vaspitnog stila otuda što su ovi autori skloni shvatanju da 'nesinhronizovani' roditelji upućuju deci duple poruke u pogledu očekivanja i ograničenja, što dete lišava jasnih pravila ponašanja i negativno se odražava na njegovu prilagođenost na školske zahteve (Rimm \& Lowe, 1988). Istraživanja ovog problema, takođe, pokazuju da se vaspitni stilovi roditelja češće percipiraju neusaglašenim u periodu adolescencije, nego u preadolescentnoj dobi (Johnson et al., 1991), što doprinosi boljem razumevanju veće učestalosti podbacivanja darovitih učenika u periodu adolescencije.

\section{ZAKLJUČAK}

Oblast psihologije darovitosti koja je ponikla na pokušaju tumačenja razvoja talenta pod okriljem porodice predstavlja 'klizav teren' za izvođenje opštih zaključaka. Moglo bi se reći da nakon postizanja konsenzusa o tome da porodični 
uticaji imaju karakter podupiranja, ali ne i produkovanja izuzetnosti, ispitivanja specifičnih aspekata funkcionisanja porodica sa darovitim detetom retko kad nude jednoznačne i celovite odgovore. Kad je reč o vaspitnim postupcima roditelja, koje je moguće sistematizovati duž dveju dimenzija, najveći stepen saglasnosti nalaza konstatuje se u slučaju ispitivanja uloge afektivne responsivnosti roditelja u razvoju talenta, otuda što se topao i prihvatajući stav roditelja pokazao dosledno povezanim sa visokim stepenom ostvarenosti detetovih potencijala. Sa druge strane, uvidom $\mathrm{u}$ nalaze istraživanja relacija kontrole u vaspitanju i aktualizacije potencijala, pokušaji izvođenja opštih zaključaka se unekoliko komplikuju. Naime, iako ne postoji sumnja u vezi shvatanja kontrole kao usmeravanja i vođenja deteta, izvesne nedoumice proizilaze iz pokušaja utvrđivanja optimalnog intenziteta ove dimenzije. Ove nedoumice se $u$ izvesnoj meri prevazilaze relativizovanjem ovog problema, te zapažanjem da se primerenost stepena kontrole u vaspitanju darovitog deteta mora vrednovati u odnosu na njegov uzrast i domen manifestovanja darovitosti. Ovim je moguće objasniti i različita shvatanja optimalnog vaspitnog stila za razvoj darovitosti, koja afektivnu dimenziju kombinuju i sa ograničavanjem u vaspitanju (autoritativni vaspitni stil), ali i sa fleksibilnim vaspitnim pravilima (popustljivi vaspitni stil).

\section{LITERATURA}

Bloom, B. (1985). Developing talent in young people. New York: Ballantine Books.

Cambel. J. R.(1997). Raising your child to be gifted. Cambridge, MA: Brookline books.

Chan, D.W. (2008). Giftedness of Chinesse students in Honk Kong: percpectives from different conceptions of intelligence. Gifted Child Quarterly, 52(1), 40-54.

Conrade, G., \& Ho, R. (2001). Differential parenting styles for fathers and mothers: Differential treatment for sons and daughters. Australian Journal of Psychology, 53, 29-35.

Cornell, D. G., \& Grossberg, I. W. (1987). Family environment and personality adjustment in gifted program children. Gifted Child Quarterly, 31(2), 59-64.

Cross, T.L. \& Coleman, L. J. (2005). School based conception of giftedness. 
U: R. J. Sternberg \& J. E. Davidson (Eds.), Conceptions of giftedness (str. 52-63). New York: Cambridge University Press.

Dornbusch, S. M., Ritter, P. L., Leiderman, P. H., Roberts, D. F. \& Fraleigh, M. J. (1987). The relation of parenting style to adolescent school performance. Child Development, 58(5), 1244-1257.

Dwairy, M. (2004). Parenting styles and mental health of Arab gifted adolescents. Gifted Child Quarterly, 48(4), 275-286.

Fajgelj, S. (2004). Metode istraživanja ponašanja. Beograd: Centar za primenjenu psihologiju.

Feldman, D. H. \& Goldsmith, L. T. (1991). Nature's gambit: Child prodigies and the development of human potential. New York: Teachers College Press.

Freeburg, N.E. \& Payne, d.t. (1967). Parental influence on cognitive development in early childhood. Child Development, 38, 65-87.

Freeman, J. (1998). Educating the very able: current international reserch. London: The stationary office.

Freeman, J. (2000). Families: the essential context for gifts and talents. U: K. A. Heller, F. J. Mönks, R. J. Sternberg \& R. Subotnik (Eds.). International handbook of giftedness and talent (str. 573-587). Oxford: Elsevier science.

Gagné, F. (2005). From gifts to talents: The DMGT as a devalopmental model. U: R. J. Sternberg \& J. E. Davidson (Eds.), Conceptions of giftedness (str. 98-120). New York: Cambridge University Press.

Genc, L. (1988). Dimenzije vaspitanja i razvoj ličnosti: teorija i istraživanja. Psihologija, 4, 121-132.

Geppert, U. \& Kuster, U. (1983). The emergence of ,wanting to do it onself": A precursor of achievementmotivation. International Journal of Behavioral Development, 6, 355-365.

Getzels, J.W. \& Jackson, P.W. (1962). Creativity and intelligence: Explorations with gifted students. New York: Wiley.

Hau, K. T., \& Salili, F. (1996). Achievement goals and causal attributions of Chinese students. U: S. Lau (Ed.), Growing up the Chinese way (str. 121-145). Hong Kong: The Chinese University Press.

Heller, K. A., Perleth, C. \& Lim, K. (2005). The munich model of giftedness designed to identify and promote gifted students. U: R. J. Sternberg \& J. E. Davidson 
(Eds.), Conceptions of giftedness (str. 147-170). New York: Cambridge University Press.

Hickman, G. P., Bartholomae, S., \& McKenry, P. C. (2000). Influence of parenting styles on the adjustment and academic achievement of traditional college freshmen. Journal of College Student Development, 41, 41-54.

Johnson, B. M., Shulman, S., \& Collins, W. A. (1991). Systemic patterns of parenting as

reported by adolescents: Developmental differences and implications for psychosocial outcomes. Journal of Adolescent Research, 6, 235-252.

Karnes, M. B., \& Shwedel, A. (1987). Differences in attitudes and practices between fathers of young gifted and fathers of young nongifted children: A pilot study. Gifted Child Quarterly, 31, 79-82.

Kodžopeljić, J. Štula, J. i Genc, A. (2008). Relacije između vaspitnih stavova roditelja i autoritarnosti dece. Pedagoška stvarnost LIV(9-10), 1027-1039.

Lacković-Grgin, K. (2006). Psihologija adolescencije. Jatrebarsko: Naklada Slap.

Landau, E. \& Weissler, K. (1993). Parental environment in families with gifted and nongifted children. Journal of Psychology, 127(2), 129-142.

McKinney, C. \& Renk, K. (2008). Differential parenting between mothers and fathers: Implications for late adolescents. Journal of Family Issues, 29(6), 806827.

Olszewski-Kubilius, P. (2002). Parenting practices that promote talent development, creativity, and optimal adjustment. U: M. Neihart, S. M. Reis, N. M. Robinson, \& S. M. Moon (Eds.), The social and emotional development of gifted children: What do we know? (str. 205-212). Waco, TX: Prufrock Press.

Paris, S. G., Morrison, F. J. \& Miller, K. F. (2006). Academic pathways from preschool through elementary school. U: P. A. Alexandar, \& P. H. Winn (Eds.), Handbook of Educational Psychology, 2nd edition (str. 61-85). Mahwag, N.J.: Lawrence Erlbaum Associates.

Peterson, J.S (2011). Successful adults who were once adolescent underachievers. Gifted Child Quarterly, 45(4), 236-250.

Phares, V. (1999). "Poppa” psychology. Westport, CT: Praeger.

Piper, L. \& Naumann, T.F. (1974). Home environment variables and gifted 
young children: An ecological inquiry. Ellensburg, Washington: Central Washington State College.

Rimm, S. \& Lowe, B. (1988). Family environments of underacieving gifted students. Gifted Child Quarterly, 32(4), 353-359.

Rot, N. (1994). Osnovi socijalne psihologije. Beograd: Zavod za udžbenike i nastavna sredstva.

Russell, A., Aloa, V., Feder, T., Glover, A., Miller, H., \& Palmer, G. (1998). Sex-based differences in parenting styles in a sample with preschool children. Australian Journal of Psychology, 50, 89-99.

Schilling, S. R., Sparfeldt, J. R. \& Rost, D. H. (2006). Families with gifted adolescents. Educational Psychology, 26(1), 19-32.

Stevenson, H.W., Lee, S.Y. \& Stigler, J.W. (1986). Mathematics achievement of Chinese, Japanese and American children. Science, 231, 639-699.

Stevenson, H. W., \& Lee, S. (1996). The academic achievement of Chinese students. U: M. H. Bond (Ed.), The handbook of Chinese psychology (str. 124-142). Hong Kong: Oxford University Press.

Tein, J. Y., Roosa, M. W. \& Michaels, M. (1994). Agreement between parent and child reports on parental behaviors. Journal of Marriage and Family, 56, 341355.

Weissler, K. \& Landau, E. (1992). Characteristics of families with no, one or more than one gifted child. Journal of psychology, 127(2), 143-152.

Winner, E. (1996). Gifted children: Myths and realities. New York, Basic Books.

Jasmina Pekić

PARENTAL REARING PRACTICES AND DEVELOPMENT OF GIFTEDNESS

\section{Summary}

The paper offers an overview of research regarding the relation of parental rearing practices and development of high potential, taking into account the two-dimensional models. When it comes to the emotional dimension, there is a high degree of consistency in 
empirical findings which suggest importance of parental emotional warmth in the development of children's abilities. On the other hand, research on the role of control in upbringing of gifted child generate different conclusions. Although there is no doubt related to perceptions of control as directing and managing the child, some uncertainties arise from attempts to determine the optimal intensity of this dimension. Finally, although it is difficult to give an unambiguous answer about the optimal combination of parental rearing practices, because of the fact that this issue must be considered in relation to specific domain of giftedness, as well as gifted child's age, research on this problem in most cases suggest a positive correlation between the authoritative rearing style and children's talents.

Keywords: giftedness, parental rearing practices, two-dimensional upbringing models, authoritative style. 